\title{
Ideologias lingüisticas: Diferencias entre hombres y mujeres de clase alta de Galicia y de Cataluña
}

\author{
Daniel Pinto PaJares \\ Investigador en sociolingüística \\ Universidad de Vigo \\ Facultad de Filología y Traducción \\ Departamento de Lengua Española \\ Universidad de Vigo \\ 36310 Vigo (España) \\ E-mail: danielpinto@uvigo.es
}

\section{LINGUISTIC \\ DIFFERENCES \\ UPPER CLASS MEN AN OF GALICIA AND CATALONIA}

RESUMEN: Distintas disciplinas han detectado diferencias en el habla de hombres y mujeres, llegando a la hipótesis de que las mujeres tienden a privilegiar las lenguas dominantes como recurso simbólico para asegurar su visibilidad en la sociedad. En este artículo abordamos las diferencias de hombres y mujeres de clase alta de Galicia y de Cataluña respecto a sus ideologias lingüísticas hacia el castellano y hacia el gallego y catalán, respectivamente. Mediante entrevistas semidirigidas, hemos extraído los discursos de dieciséis personas de clase alta que tratan aspectos como las preferencias lingüisticas en interacciones coloquiales o las valoraciones del gallego y del catalán cuando compiten con el castellano por su hegemonía. Las diferencias detectadas permiten establecer un paradigma por el cual los hombres forman fracciones sociales y las mujeres conforman estratos sociales dado el irregular valor simbólico que supone la elección lingüística entre ellos.

PALABRAS ClAVES: fracción social; estrato social; normalización femenina; lengua minorizada; ideologias lingüisticas.

SUMARIO: 1. Introducción. 2. Estado de la cuestión. 3. Metodología. 4. Resultados de la investigación. 5. Fracciones y estratos sociales. 6. Conclusión.
ABSTRACT: Several disciplines have detected differences in men and women's speech. The obtained hypothesis is that women are inclined to privilege dominant language as a symbolic resource to ensure their visibility in society. In this paper, we address the differences between upper class men and women from Galicia and Catalonia with respect to their linguistic ideologies towards Spanish and Through semi-structured interviews, we have extracted the discourses of sixteen upper class people that deal with aspects such as linguistic preferences in colloquial interactions or the valuations of Galician and Catalan whenever they compete with Spanish for their hegemony. The differences detected allow to establish a paradigm by which men form social fractions and women form social strata given the irregular symbolic value that the linguistic choice supposes between them.

KEY WORDS: social fraction; social stratum; female normalisation; minoritized language; language ideologies.

SUMMARY: 1. Introduction. 2 State of the issue. 3. Methodology. 4. Results of the research. 5. Social fractions and social strata. 6. Conclusion. Galician and Catalan, respectively.

\section{LES IDÉOLOGIES LINGUISTIQUES DIFFÉRENCES ENTRE HOMMES ET FEMMES DE LA CLASSE SUPÉRIEURE EN GALICE ET EN CATALOGNE}

RÉSUMÉ: Certaines disciplines ont détecté des différences dans les discours des hommes et des femmes; aboutissant à l'hypothèse que les femmes ont tendance à privilégier les langues dominantes en tant que ressource symbolique pour assurer leur visibilité dans la société. Cet article aborde les différences entre les hommes et les femmes de la classe supérieure de Galice et de Catalogne par rapport à leurs idéologies linguistiques envers l'espagnol, et le galicien et le catalan, respectivement. À travers des entretiens semi-dirigés, nous avons extrait les discours de seize personnes qui traitent les préférences linguistiques dans les interactions familières ou les évaluations du galicien et du catalan lorsqu'ils rivalisent avec l'espagnol pour leur hégémonie. Les différences détectées permettent d'établir un paradigme selon lequel les hommes forment des fractions sociales et les femmes des strates sociales, compte tenu de la valeur symbolique irrégulière que suppose le choix linguistique entre eux.

MOTS CLÉS: fraction sociale; strate social; normalisation féminine langue minorisée; idéologies linguistiques.

SOMMAIRE: 1 . Introduction. 2. État de la question. 3. Méthodologie. 4. Résultats de la recherche. 5. Fractions sociales et strates sociales. 6. Conclusion.
Fecha de Recepción Fecha de Revisión Fecha de Aceptación Fecha de Publicación 


\title{
Ideologias Lingüisticas: Diferencias entre hombres y mujeres de clase alta de Galicia y de Cataluña
}

\author{
DANIEL PINTO PAJARES
}

\section{INTRODUCCIÓN}

Distintas áreas del conocimiento como la antropología y la sociología han investigado el rol subordinado de las mujeres en numerosas sociedades del mundo. Existe una tendencia generalizada que potencia la reclusión de la mujer en la esfera doméstica y, aun cuando está presente en ámbitos profesionales, persiste la imagen biologizada de la mujer madre, dedicada al cuidado de la familia, mientras que el poder se negocia en ámbitos públicos dominados por hombres (Rosaldo y Lamphere, 1974). La percepción que las personas tienen de su sexo se construye mediante procesos histórico-culturales que configuran funciones y fomentan comportamientos determinados.

Esta estructuración sociocultural influida por el sexo se manifiesta en el comportamiento lingüístico. Numerosas investigaciones exponen diferencias lingüísticas entre hombres y mujeres, fenómeno que llevó a Glück (1979: 61) a proponer el concepto de generolecto como estilo discursivo organizado bajo la variable del género. Esta noción no ha estado exenta de críticas dado que la distancia en la que se basan otras variedades lingüisticas como los dialectos y los sociolectos no es válida para explicar la variación de género, pues esta es producto de diferencias construidas social y culturalmente (Trudgill, 1983). Otras etiquetas como "women's language" (Thorne y Henley, 1975: 269), "female register" (Rosenblum, 1986: 157) o "women's style" (Mulac y Bradac, 1995: 83) aluden a constructos estereotipados que marcan la frontera entre el habla de mujeres y hombres. Estas demarcaciones configuran ideológicamente las identidades masculina y femenina sobre la base del discurso.

En este estudio, nos centramos en las ideologías lingüísticas como fenómeno de variación entre hombres y mujeres. El objeto de análisis consiste en un grupo de hombres y mujeres de Galicia y de Cataluña de clase alta. Como veremos a continuación, la clase social no ha sido tratada de manera extensiva por la sociolingüistica en lo que se refiere a su conjunción con la variable sexo en los estudios de ideologías lingüísticas de ambos territorios. El objetivo de esta investigación es doble: por un lado, detectamos la influencia del sexo en las diferencias sobre las ideologias lingüisticas de dos grupos de informantes de clase alta de Galicia y de Cataluña; por otro lado, con base en la fluctuación social que producen estas diferencias, proponemos divisiones sociales en el seno de la clase alta que engendran una estructuración que puede repercutir en aspectos de normalización lingüística. 


\section{EsTAdo DE LA CUESTIÓN}

A partir de la década de 1970 se generaliza la importancia del sexo como variable funcional para explicar fenómenos sociolingüísticos. En distintos niveles del análisis lingüístico se han detectado diferencias sustanciales en el habla de hombres y mujeres. En el nivel fonético, algunos estudios canónicos como los de Trudgill (1974), Macaulay (1978) y Eckert y McConnellGinet (1999) muestran la tendencia de las mujeres a emplear formas de prestigio. En el nivel gramatical también se han detectado parámetros por los que las mujeres son más sensibles a las formas lingüísticas socialmente aceptadas y los hombres se decantan por las formas no estándares (Eisikovits, 1998).

Respecto al tema concreto que proponemos en esta investigación, hemos encontrado un vacío investigativo cuando se trata de comparar las ideologías lingüisticas de hombres y mujeres con un perfil socioeconómico favorable en Galicia y en Cataluña. No obstante, es posible encontrar algunos trabajos orientados en una línea cercana. Como punto de partida, cabe señalar que históricamente el gallego y el catalán no han producido capitalizaciones equiparables en sus respectivas comunidades lingüísticas.

Desde principios del siglo XX se recogen valoraciones sobre el gallego que denotan atraso, ruralidad y pobreza, por lo que uno de los prototipos de hablante hace referencia a la clase baja rural (Lorenzo Suárez, 2009). Con el impulso de las reivindicaciones culturales gallegas al término del Franquismo, emerge un tipo de hablante cuya lengua primera es el castellano pero, motivado por razones de indole sociopolítica, decide adoptar el gallego como lengua habitual. A estos hablantes se les denomina neofalantes y, pese a representar un perfil laboral liberal y cultural ilustrado, no gozan de altas consideraciones en tanto que se les supone una pretensión política y no son percibidos como hablantes puros (Ramallo, 2013).

Respecto a las diferencias de capitalizaciones entre hombre y mujeres, desde la década de 1930 se apuntaba a una mayor complicidad de las mujeres de clase alta por el castellano (Sanmartín Rei, 2002). Hasta entrado el siglo XXI no se tomó en consideración el género como variable sistemática en los estudios sociolingüísticos y en las encuestas demolingüísticas. En esos años, el Censo de Poboación e Vivendas de 2001 (IGE, 2001: http:/ / www.ige.eu/web/mostrar_actividade_estatistica.jsp?idioma=gl\&codigo $=0206002002$, fecha de consulta: 05/07/18) señaló un menor uso del gallego por las mujeres que por los hombres, y el Seminario de Sociolingüística del 2003 (RAG, 2003) mostró evaluaciones más estereotipadas sobre las mujeres en dimensiones como la competencia lingüística en gallego y en la oposición entre hablas tradicionales y hablas vinculadas con el éxito social.

En estudios cualitativos más recientes, las mujeres gallegas identifican como ignorantes a las mujeres que hablan habitualmente en gallego y asocian el castellano con el refinamiento (González Veira y Seoane Bouzas, 
2010). El vínculo del gallego y del castellano con funciones antitéticas implica que el primero se acerca a formas vulgares vinculadas con la proximidad o el afecto (Sanmartín Rei, 2009). En este sentido, Moure (2010) subraya el abandono del gallego por parte de las mujeres para acercarse a los valores de refinamiento que les aportaría el castellano.

En Cataluña, la identidad étnica y el alto nivel socioeconómico que han detentado las personas catalanohablantes en los últimos siglos ha permitido que el catalán alcance una alta reputación como garante de prestigio y progreso socioeconómico (Woolard, 1997). La estructura estatal vertebrada sobre la preponderancia del castellano no ha impedido que los juicios que evocan mayor prestigio y características positivas recaigan del lado de la lengua minorizada, el catalán (Woolard, 1985).

En las últimas dos décadas se generalizan las investigaciones que dan importancia a la variable sexo. El Idescat (2004) muestra que las mujeres sustituyen el catalán por el castellano en mayor proporción que los hombres, aunque no se detecta una disparidad reseñable en cuanto a la lealtad lingüística hacia ambas lenguas en las interacciones cotidianas. Más recientemente, se aprecia un descenso generalizado del uso del catalán, que alcanza las mismas cotas en hombres y mujeres, mientras que el empleo del castellano es mayor en estas últimas (Idescat, 2015).

En el estudio cualitativo de Pujolar (2003), que entrevista a un grupo de jóvenes barceloneses, se concluye que las mujeres sienten predilección por los trazos lingüísticos y las formas culturales mejor valorados socialmente. Este autor, además, abre un debate en torno a la conceptualización del espacio, un plano analítico que considera alejado del método investigador. Existe una dimensión intermedia entre los datos derivados de las interacciones comunicativas y las explicaciones sobre la formación de estructuras sociales de desigualdad. Este plano intermedio se compone de "contextos locales de participación social" (Pujolar, 2003: 487), que aluden a los ámbitos que contextualizan la situación comunicativa y que posibilitan la inteligibilidad de la relación entre las prácticas observadas y los análisis que de ellas se derivan.

El autor toma este concepto de la noción clásica de "campo" (Bourdieu, 1982a). Los campos son los espacios sociales donde interactúan los agentes con base en relaciones definidas por la posesión de formas especificas de capital. Dentro del campo en el que tiene lugar la interacción, se refleja la apropiación de los capitales simbólicos por determinados agentes en función de una lucha entre las competencias lingüisticas de cada uno. En esta interacción, unos agentes tratan de preservar el orden simbólico existente y otros tratan de subvertirlo. Consecuentemente, se producen fisuras en las diferentes estructuras de los grupos sociales.

Dado que en este trabajo tomamos la clase social como entidad vertebradora del espacio social, conviene destacar la división propuesta por Poulantzas (1968) en torno a estas fisuras. Este autor establece los conceptos de "fracción social" y "estrato social" como conjuntos sociales compuestos por 
miembros que comparten un cierto estilo de vida y características comunes como el poder adquisitivo. Las diferencias económicas, sociales o de otra indole entre los sujetos pueden conducir a la formación de grupos que juegan un papel desigual de fuerzas sociales. Las fracciones son susceptibles de ejercer una influencia social eventual en tanto que el nivel de autonomía alcanzado se funda en su sustrato como fuerzas sociales. Sin embargo, los estratos son grupos más volátiles desde el punto de vista de su cohesión interna.

Una de las variables que articula esta lucha simbólica y que, con base en ella, pueden conformarse fracciones y estratos, es el sexo de los participantes en la interacción. Tal y como hemos visto anteriormente, en ciertos contextos las mujeres parecen sentir predilección por las formas de prestigio. Estas preferencias se han explicado atendiendo a la mayor inseguridad social que sufren las mujeres. Para Bourdieu (1982a), esta singularidad atiende a la mayor importancia que representa el capital simbólico para las mujeres dada la diferencia de parámetros educativos y oportunidades laborales entre sexos, de manera que la lengua se convierte en un recurso simbólico crucial para ellas.

No obstante, existen excepciones a una pretendida regla general que ponen de manifiesto que el sexo no condiciona por sí solo las prácticas lingüísticas. Las teorias sobre el análisis del sexo que se establecieron en las primeras décadas del siglo XX giraban en torno al "dominio" y a la "diferencia" (Serrano, 2008: 178). Por un lado, las teorias sustentadas sobre el dominio implicaban asumir que la socialización es el factor que desencadena las diferencias principales entre hombres y mujeres; por otro lado, las concepciones basadas en la diferencia interpretaban que los roles lingüísticos están dados de antemano. Una perspectiva actual considera que estas divergencias han de observarse en relación con los interlocutores y con el momento de la interacción, influido en gran medida por el contexto cultural (Eckert y McConnell-Ginet, 2003). De esta manera, el sexo no construye comportamientos lingüísticos de una manera aislada, sino que actúa en conjunción con otros elementos.

Para Bourdieu (1982a), la mediación del contexto cultural en la adopción de formas lingüísticas implica una hegemonía en la que dos estructuras socioculturales del Estado muy específicas como son la familia y la escuela construyen el reconocimiento de las variedades lingüísticas estándar como formas prestigiosas. En este sentido, Woolard (1985) cuestiona que la hegemonía lingüistica dependa de la dominación institucional de una lengua y, como argumento, expone la resistencia de la comunidad catalanohablante a varias décadas en las que el rol de las instituciones castellanizadas no ha conseguido establecer la hegemonía lingüística en torno al castellano.

La explicación que propone esta autora reside en el factor socioeconómico. El Franquismo no consiguió destruir la economía de Cataluña, por lo que la burguesia catalana, tradicionalmente ligada a valores étnicos y lingüísticos catalanizados, dominó la economía privada regional. Aunque los 
organismos oficiales estaban influidos por el nacionalismo español que imponía el castellano como lengua única, el catalán dominaba en los encuentros de carácter socioeconómico: eran los catalanohablantes quienes ocupaban puestos directivos en las empresas o quienes residian en barrios más lujosos, entre otros ejemplos. Así pues, en contradicción con el modelo propuesto por Bourdieu (1982a), el paradigma catalán representa un contraejemplo a su teoria de la hegemonía lingüística.

\section{Metodología}

\subsection{ACCESO A LAS PERSONAS PARTICIPANTES}

La toma de contacto con las personas entrevistadas ha partido de dos indicios puesto que no es posible conocer de antemano sus perfiles socioeconómicos. En primer lugar, hemos seleccionado las empresas catalanas que percibieron beneficios superiores a los 15 millones de euros en 2014, lo cual representa el $2,56 \%$ del total, y las empresas gallegas que obtuvieron más de 5 millones de euros en el mismo año, el 0,96\% del total (Camerdata, 2015: http://www.camerdata.es/php/Productos/rankings.php, fecha de consulta: 20/05/18). Este desequilibrio entre ambos territorios se justifica a partir de la asimetría en la actividad económica de cada uno. En segundo lugar, solo hemos seleccionado las empresas cuya plantilla superase los 500 trabajadores en 2014 como indicador de una fuerte repercusión económica en el mercado. Ambos criterios toman datos del año 2014 dado que la recopilación de las entrevistas se llevó a cabo en 2016 en el marco de una investigación más amplia (Pinto Pajares, 2018).

Estas características no son garantía de encontrar a informantes de clase alta en la esfera empresarial. Sin embargo, ambos indicadores apuntan a una presencia económica importante en los mercados financieros que denota un alto capital económico de sus directivos y una repercusión social bien establecida que, además, va acompañada de un capital simbólico potente. Los datos relativos a los dos factores que se han comentado han sido extraídos, en unos casos, a través de las páginas web de las empresas y, en otros casos, en portales como El Economista (2015: http://ranking-empresas.eleconomista.es/, fecha de consulta: 20/05/18) o Expansión (2015: http://www.expansion.com/empre-

sas/2015/09/11/55f3368fe2704e77618b4587.html, fecha de consulta: $20 / 05 / 18)$, entre otros.

Cabe señalar el gran rechazo que hemos encontrado al solicitar citas con las personas directivas mediante los servicios de atención al cliente o de recursos humanos de las empresas. Finalmente, tras conseguir citar a dieciséis informantes, las entrevistas se llevaron a cabo entre los meses de abril y diciembre de 2016 y se grabaron en presencia del investigador y bajo el conocimiento y autorización de los participantes en los lugares elegidos por ellos, normalmente en despachos de sus respectivos centros de trabajo. 


\subsection{TRABAJO DE CAMPO}

La producción de datos de esta investigación cualitativa comienza con un cuestionario que cumple dos finalidades: identificar a cada persona mediante datos como el nombre, la edad y el origen geográfico, y conocer sus perfiles socioeconómicos. Para este segundo objetivo, hemos incluido diversas preguntas que revelan la formación académica, el sector económico de la actividad laboral, el cargo ejercido en la empresa, el salario neto anual, las formas de asociacionismo en las que participan y, por último, les hemos solicitado que indicasen los premios y reconocimientos adquiridos por méritos de diversa índole. La conformación de estas características manifiesta un perfil socioeconómico determinado que hemos contrastado con la configuración de requisitos para considerar clase alta a estas personas y cuyos detalles indicamos en el siguiente apartado.

La segunda etapa en la producción de datos corresponde a una entrevista individual en profundidad de unos 40 minutos de duración. Además, su carácter de entrevista semidirigida permite que, lejos de buscar respuestas estancas, las personas entrevistadas hayan sido libres de desviarse de la pregunta inicial para obtener un discurso elaborado que incluyera matices que no hubiéramos detectado de otro modo. La entrevista se ha estructurado en cinco bloques según la temática.

El primer bloque ha centrado su atención en una visión biográfica retrospectiva para obtener información relativa a los orígenes sociales, relaciones familiares o carrera académica y profesional. A continuación, hemos preguntado en qué lengua los informantes responderian ante diferentes tipos de hablantes para averiguar aspectos como la lengua no marcada o si la jerarquía social influye en esta decisión. El tercer bloque trata la influencia del gallego y el catalán en el ámbito empresarial y en su proyección internacional, aspectos relacionados con cuestiones de cariz utilitarista. Posteriormente, hemos incluido preguntas relativas a la aceptación o rechazo de los procesos de normalización lingüística para averiguar la legitimidad asignada. Por último, hemos enunciado una serie de afirmaciones que guardan prejuicios muy concretos y hemos pedido a los participantes que indicasen su conformidad según una escala numérica, lo cual nos ha permitido suplir carencias de información durante el discurso. A continuación reproducimos una parte de dichos enunciados:

1) El castellano es más útil que el catalán/gallego para comunicarse con cualquier habitante de España.

2) Para proteger al catalán/gallego, hay que privilegiar su uso en todas las administraciones públicas de Cataluña/Galicia.

3) El objetivo de la inmersión lingüística en catalán/gallego es que no haya minorías monolingües en castellano. 
4) El castellano está amenazado en Cataluña/Galicia porque se privilegia al catalán/gallego en todos los ámbitos.

5) El castellano debería tener menor peso que el gallego en las interacciones entre miembros de la empresa.

La transcripción de las entrevistas ha seguido un sistema de puntuación propio del análisis del discurso, de manera que nos hemos centrado en la coherencia argumental y los tópicos expuestos por los informantes, dejando a un lado un nivel más detallado que incluyese el análisis de gestos, falsos comienzos o silencios, entre otras características. La codificación posterior se ha realizado mediante un proceso manual en el que, después de insertar observaciones en las transcripciones de los testimonios, se procedió a identificar temas y subtemas que facilitasen el análisis y las interpretaciones.

\subsection{PERFIL DE LAS PERSONAS ENTREVISTADAS}

Se ha pretendido que el objeto de investigación fuera variado y paritario en torno a tres ejes: (i) garantizamos un equilibro entre sexos, de manera que el grupo de participantes está compuesto por ocho hombres y ocho mujeres; (ii) para fomentar discursos de personas que socializan de diferentes maneras en el ámbito laboral, procuramos la heterogeneidad relativa a los sectores económicos, entre ellos, la agroalimentación, la industria, los servicios y las nuevas tecnologías; y (iii) los informantes proceden de diferentes provincias catalanas y gallegas para proveer modelos de diferentes ámbitos territoriales.

Para elaborar el perfil social de clase alta que deben cumplir las personas participantes en este estudio, se han elegido una serie de requerimientos que hacen recordar el sistema de capitales de Bourdieu (1979).

1) Salario neto anual: algunos estudios como la encuesta anual de estructura salarial realizada por el INE (2015) (http://www.ine.es/dyngs/INEbase/es/operacion.htm?c=Estadis-

tica_C\&cid=1254736061721\&menu=ultiDatos\&idp=1254735976596, fecha de consulta: 13/06/18) y la base de datos The World Top Incomes Database (Soriano, 2015: http://www.libremercado.com/2015-0514/los-ricos-en-espana-ni-son-tantos-ni-son-tan-ricos-1276547799/, fecha de consulta: 13/06/18) establecen unos tramos salariales del 10\% más rico de la sociedad que varía en función del sexo y del territorio. Tras someter a crítica estos datos, dado que revelaban cantidades sustancialmente bajas como para denominar clase alta a una persona, decidimos aumentar cada cantidad en un $50 \%$, de manera que obtuvimos los siguientes tramos salariales: $100.146 €$ los hombres catalanes, $75.027 €$ las mujeres catalanas, $81.474 €$ los hombres gallegos y $62.430 €$ las mujeres gallegas. 
2) Formación académica: es condición poseer títulos académicos que den acceso a la ocupación laboral ejercida y que consolide un estatus alto sobre la base de conocimientos y no sobre recursos heredados. Así desechamos un perfil de clase alta caracterizado por la ociosidad o por los recursos heredados, aquello que Wright (2004: 29) categorizó como "iddle rich".

3) Red social: las personas entrevistadas tienen que defender los intereses de clase mediante la socialización con miembros de diversos ámbitos que sean percibidos en términos de rentabilidad socioeconómica. Eckert (2000) asegura que, en estos espacios interaccionales, los significados se construyen socialmente, por lo que la pertenencia a determinadas comunidades de práctica es crucial en tanto que sus miembros adoptan ideologias consagradas en dicho núcleo de interacción. Las formas particulares que adoptan estas redes sociales dependen de su naturaleza. Así, si su eje vertebrador es una ideología política concreta, esta red social puede adquirir la conceptualización de "partido político". Si, por el contrario, el elemento transversal es de índole cultural o económica, diremos que la forma particular de asociacionismo se da en una organización con una inquietud cultural concreta o en un club financiero, respectivamente.

4) Rango laboral: es crucial detentar un puesto directivo dentro de la empresa o cualquier otra ocupación de alto rango que implique estar a cargo de empleados.

5) Legitimidad simbólica: la conjunción de los requisitos anteriores junto con otros criterios como la obtención de premios por motivos laborales y sociales permite ser percibido como agente social legítimo (Bourdieu, 1982b).

Para ser objeto de investigación, estas personas debian reunir, al menos, cuatro de las propiedades anteriores. Aunque somos conscientes de que la legitimidad simbólica es la más controvertida de valorar, todas las personas entrevistadas cumplen con los demás componentes, por lo que su perfil simbólico de cara a la sociedad queda asegurado. A continuación se especifican estos criterios en cada informante:

\begin{tabular}{|c|c|c|c|c|}
\hline $\begin{array}{l}\text { Requisito } \\
\text { Pseudónimo }\end{array}$ & $\begin{array}{c}\text { Salario neto } \\
\text { anual }(\boldsymbol{\Theta})\end{array}$ & $\begin{array}{l}\text { Formación } \\
\text { académica }\end{array}$ & Red social & Rango laboral \\
\hline Diego & 91-100mil & Licenciatura & $\begin{array}{l}\text { Asociación cultu- } \\
\text { ral }\end{array}$ & Director Gerente \\
\hline Jaime & 101 mil-más & Licenciatura & Club deportivo & $\begin{array}{l}\text { Director admi- } \\
\text { nistrativo y Di- } \\
\text { rector General }\end{array}$ \\
\hline Fernando & 101mil-más & Máster & $\begin{array}{l}\text { Club deportivo y } \\
\text { asociación cultu- } \\
\text { ral }\end{array}$ & $\begin{array}{l}\text { Gerente, admi- } \\
\text { nistrador y con- } \\
\text { sultor }\end{array}$ \\
\hline
\end{tabular}




\begin{tabular}{|c|c|c|c|c|}
\hline Héctor & 101 mil-más & Máster & Club financiero & $\begin{array}{c}\text { Director de Re- } \\
\text { laciones Labora- } \\
\text { les y profesor } \\
\text { Derecho Laboral }\end{array}$ \\
\hline Sara & $81-90 \mathrm{mil}$ & Licenciatura & Club deportivo & $\begin{array}{c}\text { Responsable de } \\
\text { Activación y Lo- } \\
\text { gística y Res- } \\
\text { ponsable Marke- } \\
\text { ting y Comuni- } \\
\text { cación }\end{array}$ \\
\hline Elisa & $81-90$ mil & Licenciatura & $\begin{array}{c}\text { Club deportivo y } \\
\text { asociación cultu- } \\
\text { ral }\end{array}$ & $\begin{array}{c}\text { Directora de Co- } \\
\text { municación y } \\
\text { Relaciones Insti- } \\
\text { tucionales }\end{array}$ \\
\hline Nuria & 101 mil-más & Máster & $\begin{array}{c}\text { Asociación cultu- } \\
\text { ral }\end{array}$ & $\begin{array}{c}\text { Directora gene- } \\
\text { ral adjunta y } \\
\text { consultora }\end{array}$ \\
\hline Alejandra & $\begin{array}{c}101 \text { mil-más } \\
\text { (dato inferido a } \\
\text { causa de no } \\
\text { contestación) }\end{array}$ & Máster & $\begin{array}{c}\text { Club financiero y } \\
\text { asociación cultu- } \\
\text { ral }\end{array}$ & $\begin{array}{c}\text { Consejera, apo- } \\
\text { derada y vocal } \\
\text { del patronato }\end{array}$ \\
\hline
\end{tabular}

Tabla 1: Características individuales de las personas entrevistadas de Cataluña

\begin{tabular}{|c|c|c|c|c|}
\hline Requisito & $\begin{array}{c}\text { Salario } \\
\text { neto anual } \\
\text { (€) }\end{array}$ & $\begin{array}{l}\text { Formación } \\
\text { académica }\end{array}$ & Red social & Rango laboral \\
\hline Álvaro & 101 mil-más & Licenciatura & Club financiero & Director Gerente \\
\hline Eduardo & 101mil-más & Máster & $\begin{array}{c}\text { Club financiero, } \\
\text { club deportivo y } \\
\text { asociación cultu- } \\
\text { ral }\end{array}$ & $\begin{array}{l}\text { Director General, } \\
\text { consejero y se- } \\
\text { cretario }\end{array}$ \\
\hline Javier & 101mil-más & Licenciatura & $\begin{array}{l}\text { Organización polí- } \\
\text { tica y asociación } \\
\text { cultural }\end{array}$ & Dueño y director \\
\hline Martin & 81-90mil & Licenciatura & $\begin{array}{l}\text { Asociación cultu- } \\
\text { ral }\end{array}$ & $\begin{array}{l}\text { Director comer- } \\
\text { cial, miembro del } \\
\text { consejo y admi- } \\
\text { nistrador }\end{array}$ \\
\hline Cristina & 71-80mil & Máster & Otros & $\begin{array}{c}\text { Directora de con- } \\
\text { tratación y Ase- } \\
\text { soría Juridica, y } \\
\text { abogada }\end{array}$ \\
\hline Delia & 81-90mil & Licenciatura & Club financiero & $\begin{array}{c}\text { Directora y fun- } \\
\text { dadora }\end{array}$ \\
\hline Raquel & 81-90mil & Máster & $\begin{array}{l}\text { Asociación cultu- } \\
\text { ral }\end{array}$ & $\begin{array}{c}\text { Directora de Co- } \\
\text { mercio y Expor- } \\
\text { tación y Técnica } \\
\text { de Seguridad y } \\
\text { M-A } \\
\end{array}$ \\
\hline Laura & 101mil-más & Licenciatura & Club financiero & $\begin{array}{c}\text { Gerente y Direc- } \\
\text { tora }\end{array}$ \\
\hline
\end{tabular}

Tabla 2: Características individuales de las personas informantes de Galicia 
La Tabla 1 y la Tabla 2 describen individualmente los criterios de selección y se ha determinado que ninguno de ellos es por sí solo imprescindible para configurar un perfil de clase alta. La estructuración de ese perfil no se fundamenta sobre la base de una propiedad sino sobre la conjunción y los vínculos entre unas y otras. Aun así, hay que señalar dos casos concretos de aparente incumplimiento de un criterio de selección.

Solamente Diego se queda por debajo del salario neto anual estipulado para los hombres catalanes con una diferencia mínima de $146 €$ y un desfase máximo de $9.146 €$, aunque hemos decidido incluirle en esta investigación. Se trata de un directivo de una empresa con beneficios anuales de 20 millones de euros. Así pues, o bien su salario neto anual no se aleja de lo estipulado para este estudio, o bien seleccionó el baremo anterior al real por cuestiones de modestia o timidez.

Asimismo, Alejandra no ha querido aportar el dato de su salario neto anual, de manera que se ha tenido que inferir una aproximación a partir de cuatro factores: (i) el origen familiar y patrimonial, (ii) la facturación de las dos empresas en las que ejerce como directiva, (iii) el círculo cultural e intelectual en el que participa y (iv) su condición de personaje público para los medios de comunicación. A partir de estos detalles en los que hemos ahondado, consideramos que Alejandra cuenta con un amplio patrimonio y un salario neto anual que, probablemente, sobrepase los 75.027 euros estipulados para las mujeres catalanas.

Cabe subrayar que las personas entrevistadas no forman una muestra representativa de los diferentes grupos sociales estudiados, ya que esta investigación cualitativa tiene por objetivo dar a conocer lo particular y distintivo a partir de la identificación de tendencias que puedan ser completadas con estudios venideros.

\section{RESUltados DE LA INVESTIGACIÓN}

\subsection{LA LENGUA EN LAS INTERACCIONES COLOQUIALES}

En este apartado se exponen las diferencias detectadas entre hombres y mujeres en la elección de la lengua en interacciones coloquiales. Se ha propuesto una hipotética situación en la que un castellanohablante le pregunta en catalán/gallego a cada informante y otra en la que una persona catalana/gallega le pregunta en castellano a los participantes, los cuales han de pensar en qué lengua responderian.

En Cataluña, las mujeres emplearian la lengua de la persona que se ha dirigido a ellas, mientras que los hombres valoran la siguiente hipótesis: si se percibe que el interlocutor no entiende catalán, entonces se le responde en castellano - si P, entonces Q-. Los hombres siguen una estructura propia de la lógica proposicional que permite que haya otra opción alternativa: si se percibe que el interlocutor entiende catalán, entonces no se le responde en castellano - si no P, entonces no Q- Las mujeres, en cambio, actuarian 
con base en la decisión de sus interlocutores, adaptándose a su lengua movidas por un sentimiento de solidaridad.

En Galicia, las mujeres participantes no ponen condiciones para elegir la lengua en la que responderían. Unas declaran que lo harian en gallego y otras en castellano por una cuestión de comodidad. Esta opinión coincide con la del 36\% de las mujeres comprendidas entre los 30 y los 60 años que declaraban en 2013 contestar en la lengua en la que hablan habitualmente (IGE, 2013). Contrariamente, la elección de los hombres depende del interlocutor: "me cercioraria si esa persona verdaderamente habla gallego o no. Y si no, pues cambiaria automáticamente a español”, asegura Martín, y "se vexo que esa persona non me entende ou me pide que fale en castelán, non teño ningún problema”, declara Javier. Según el IGE (ibid), entre un 60\% y un $68 \%$ de los hombres de Galicia de 30 años en adelante declaraban en 2013 adecuarse a la lengua de sus interlocutores.

Como se observa, la variable sexo está en consonancia con la variable territorio. En conjunto, solamente los hombres catalanes exhiben cierto compromiso hacia la lengua minorizada en tanto que emplearian el catalán bajo la condición de una mutua comprensión. En el resto de informantes no se perciben indicios de compromiso hacia ninguna lengua en la medida en que las motivaciones que les guian no comportan necesariamente actitudes proactivas hacia ninguna lengua. Aun así, las mujeres gallegas y algunos hombres catalanes declaran que emplearian el castellano en la situación expuesta anteriormente. Esta inclinación hay que sopesarla considerando el contexto social de cada lengua. El uso del gallego, como lengua minorizada en Galicia, implica connotaciones ideológicas o clasistas de las que el castellano está exento, mientras que el catalán en Cataluña es entendido como un recurso de ascenso socioeconómico. En este sentido, la predilección de las mujeres por el castellano se puede entender como una adhesión a una forma de prestigio. A partir de los hombres catalanes, se comprueba un contraejemplo a la teoría de Bourdieu (1982a) respecto a la hegemonía lingüística que detentan las instituciones del Estado. Esta teoría no resulta operativa si atendemos a este grupo de informantes en tanto que el catalán goza de un alto prestigio en la sociedad de Cataluña.

\subsection{LA POSICIÓN DE LAS LENGUAS EN LA EMPRESA}

Las lenguas propias de los territorios estudiados se disputan con el castellano el espacio dentro de las empresas y los factores que desencadenan la jerarquía dependen de las políticas y de los prejuicios lingüísticos aceptados por la sociedad.

Entre los informantes catalanes, los hombres son favorables a exigir un cierto nivel de catalán al personal empleado por una cuestión de adaptación - "tú no puedes hacer bien tu trabajo, sobre todo de atención a las personas, si no conoces la lengua de una parte de la población", afirma Diego-, mientras que las mujeres ponen más trabas. Alejandra directamente se niega a ese requerimiento alegando que "hay un porcentaje de la población que no 
habla catalán; en cambio, el castellano es conocido por la totalidad" y las otras tres mujeres establecen supuestos en los que el catalán no sería necesario: Elisa afirma que "si son trabajadores que tienen que tener relación con el público, sí, imprescindible. Si no es así, no lo veo necesario"; Nuria declara que "en la [empresa] privada, yo creo que no hace falta"; y Sara opina que "si hablas con Cataluña, todos hablan castellano también. O sea que necesario no sería. Ahora, claro, si estás vendiendo, yo qué sé, fuet [risas] y tu público es la gente rural, de pueblo catalán, pues evidentemente tendrá que saber todo el mundo catalán". Las informantes catalanas no conceden espacio al catalán en las interacciones entre los empleados de la empresa, en las comunicaciones de las empresas privadas y en las que se dirijan a una clientela castellanohablante.

Cuando se trata de evaluar el predominio del catalán en la administración pública, todas las personas entrevistadas, excepto Alejandra, corroboran esa propuesta. Aparentemente, no hay incoherencia ideológica porque se puede ser sensible a la no obligatoriedad de exigir una competencia lingüística al mismo tiempo que aprobar la superposición del catalán por encima del castellano en ámbitos públicos. Sin embargo, de este planteamiento surge una contradicción: dicha superposición beneficiaria al catalán al situarla como la lengua con mayor espacio en ciertas empresas, pero la primera opinión desprende la idea de que el catalán no ha de ser una lengua con plenas funcionalidades y presencia, espacios reservados para el castellano.

En Galicia no se detecta una relación entre la lengua preferida en la empresa y el sexo de los informantes, ya que solamente Javier y Cristina apoyan establecer como requisito para los trabajadores ser competentes en gallego. La ideología lingüística contraria a esta lengua, heredada hace décadas (Lorenzo Suárez, 2009), se muestra más potente que la argumentación que formula el proceso de normalización lingüística. Si el proceso normalizador fuera combativo con ese prejuicio, cabria pensar que los informantes más jóvenes serían favorables a la exigencia del gallego en la empresa porque no habrian vivido la etapa anterior a la normalización; sin embargo, Martín y Delia, los entrevistados más jóvenes, se manifiestan igualmente en contra de esta medida.

El eje que guía a Javier y Cristina es una conciencia proactiva a favor del gallego, es decir, un factor individual. El prejuicio lingüístico en Galicia está por encima del debate normalizador mientras que, en Cataluña, este prejuicio se encuentra supeditado a las medidas que favorecen a la lengua minorizada. Esta situación revela la ineficacia de la normalización del gallego en este aspecto concreto entre la clase alta. Así pues, solamente se puede analizar este aspecto en términos de sexo en Cataluña, donde sí se observan ideologías diferenciadas. 


\subsection{LA LEGITIMIDAD DE LA NORMALIZACIÓN LINGÜÍSTICA}

Los procesos de normalización lingüística son determinantes para la vitalidad de las lenguas minorizadas ya que tratan de recuperar funciones y espacios para el código en recesión con el objetivo de frenar la sustitución por otras lenguas y garantizar la continuidad de la comunidad lingüistica (Bastardas i Boada, 1994). Se ha pedido a las personas entrevistadas valorar si la normalización lingüística del catalán y del gallego es un recurso que favorece a la comunidad lingüistica en su conjunto o si detectan sectores a los que se dé prioridad por motivos lingüisticos.

En Cataluña, solo Alejandra y Sara señalan grupos privilegiados que, por el hecho de hablar catalán, tienen más facilidad de acceso a ciertos ámbitos y recursos, como las empresas públicas, algunas páginas webs oficiales o la movilidad urbana. Paralelamente, dos mujeres gallegas, Delia y Laura, hablan de privilegios de los gallegohablantes en la administración pública y en la escuela, respectivamente. También en Galicia, Eduardo sostiene la premisa de los privilegios a los gallegohablantes, pero lo hace en términos de "discriminación positiva", concepto que no denota una alta negatividad.

En la entrevista, se han restringido las preguntas a tres circunstancias en las que el catalán y el gallego tienen una determinada presencia: las intervenciones en el Senado español, la elección de la lengua vehicular por los docentes universitarios y la inmersión lingüística en estas lenguas en la escuela.

En primer lugar, Fernando, Jaime, Alejandra, Nuria y Sara coinciden en que los servicios de traducción e interpretación en el Senado no son necesarios porque "los senadores catalanes ya saben castellano", indica Nuria, de manera que no estiman positiva la presencia del catalán en un territorio ajeno a esta lengua y en una institución de ámbito estatal. En cambio, Héctor, Diego y Elisa sí ven positivo que el catalán esté presente en este espacio: "creo que no es un gasto superficial porque, al final, que la gente se pueda expresar en su lengua, tiene un valor de proyección y de respeto", además de que "el Senado, que es la cámara de representación territorial, tiene sentido que sea así", afirma Elisa. Estos informantes entienden que el catalán puede ser utilizado sin ningún tipo de perjuicio en lugares e instituciones no asociadas directamente con la comunidad catalanohablante. Como se percibe, algunos informantes catalanes entienden como una medida fuera del sentido común el empleo del catalán más allá de los límites territoriales de la catalanofonía, mientras que ciertos hombres y una sola mujer parecen más benévolos con esta lengua en territorios externos a Cataluña.

Por el contrario, en Galicia existe unanimidad en el desacuerdo con respecto a la utilización del gallego en el Senado, excepto Javier, que declara no saber responder a esta controversia. En consecuencia, el compromiso lingüístico hacia las lenguas minorizadas no solo responde a una diferenciación de sexos sino también de territorios. Este tema no se puede tratar en clave de sexo en Galicia puesto que el prejuicio lingüistico por el cual el 
gallego no debe emplearse fuera de su territorio es más poderoso que la ideologia fomentada por la normalización lingüistica que pretende eliminar todo estigma y desconfianza hacia la utilización plena del gallego.

En segundo lugar, se ha querido averiguar las diferencias entre hombres y mujeres respecto a la lengua vehicular por parte de un docente universitario cuando se encuentra un estudiante extranjero en el aula.

En Cataluña, Elisa, Nuria y los cuatro hombres entrevistados reconocen el derecho del docente a impartir las clases en catalán, mientras que Alejandra y Sara son más reacias a este tipo de interacción. En Galicia no hay divergencias claras. Entre los hombres, solo Javier es claramente favorable a las clases en gallego; entre las mujeres, lo es Cristina. Mientras que los tres hombres restantes son rotundos en su opinión de que el profesor debería cambiar al castellano, solo Raquel es igual de tajante. Entre las otras dos mujeres, Delia comienza dudando, aunque acaba inclinándose por el castellano y Laura declara que "yo si soy el docente, funcionaria por mayorias, no por una cuestión de ideologías". Por lo tanto, existe una clara preferencia por el cambio lingüístico del docente, situación en la que no se percibe un patrón ideológico diferenciado entre hombres y mujeres.

En tercer lugar, las personas entrevistadas han valorado la inmersión lingüística en catalán y gallego desde dos perspectivas: una valoración general de esta medida y una reflexión en torno al beneficio o discriminación hacia los castellanohablantes.

En Cataluña, Diego, Jaime, Héctor, Elisa y Nuria conceden preeminencia al catalán. Entre las posturas que le otorgan menos visibilidad, Fernando y Sara proponen un modelo paritario en el que el catalán y el castellano gocen, cada uno, del 50\% de la docencia, y Alejandra reduce más la presencia del catalán al proponer una tercera lengua, el inglés, de manera que señala un sistema trilingüe en el que cada lengua dispondría de un 33\% de asignaturas. Entre estas tres personas menos leales a la presencia del catalán en la escuela, Sara y Alejandra victimizan a los castellanohablantes y consideran que la inmersión en catalán les perjudica.

En Galicia, solo Javier está de acuerdo en que el gallego tenga mayor peso en la educación. Álvaro aporta un criterio instrumental para desechar esta lengua como vehicular, aunque asegura que "bajo un punto de vista sentimental" sí prefiere el gallego, Eduardo daría libertad a los padres, y Martín propone un modelo trilingüe equilibrado entre el gallego, castellano e inglés. En cuanto a las mujeres, Laura daría libertad de elección; Cristina y Raquel, el 50\% de la docencia a cada lengua; y Delia califica de "error" que el gallego sea lengua vehicular.

\section{FRACCIONES Y ESTRATOS SOCIALES}

A partir de los datos expuestos anteriormente, no podemos englobar a los hombres y a las mujeres en grupos cerrados con claras diferencias en sus ideologías lingüísticas. Pese a ello, es posible detectar algunas inclinaciones 
que sitúan a las mujeres como agentes más proclives a privilegiar el castellano y a rechazar las prácticas lingüísticas y medidas normalizadoras que suponen una transmisión de espacios desde la lengua dominante hacia las lenguas minorizadas.

Este fenómeno es explicado por autoras como Eckert (1989) y Coates (2013) atendiendo a una mayor sensibilidad de las mujeres por la lengua de prestigio debido a la diferencia de poder social que detentan respecto a los hombres. Las mujeres, despojadas de muchas posibilidades de proyección económica, social y cultural, recurririan a la lengua dominante para asegurar su estatus a través de una herramienta simbólica como la lengua. Aparentemente, esta idea carecería de sentido aplicándose a la clase alta puesto que es un grupo social compuesto por individuos que cuentan con todo tipo de capitales y con un prestigio reconocido. Esta aparente contradicción justifica precisamente que, incluso dentro de estos círculos privilegiados, la posición social de las mujeres puede fluctuar más que la de los hombres.

La clase alta femenina conformaría, en términos de Poulantzas (1968), "estratos" sociales y la clase alta masculina se constituiría en "fracciones" sociales. Esa mayor fluctuación en mujeres que en hombres deriva de la restricción que experimentan las primeras a la hora de acceder a oportunidades de mantenimiento y acceso socioeconómico. El punto de confrontación procedente de la diferencia de sexo en la clase alta se da en términos de oportunidades, obligando a las mujeres a realizar un esfuerzo adicional para salvaguardar su posición social. Esta continua negociación y adaptación las hace constituirse en estrato social, puesto que, en tanto que grupo, no han alcanzado un nivel de autonomía equiparable al de las fracciones y, por tanto, no inciden tan poderosamente en los cambios sociales.

En ambos territorios se percibe un proceso que en algunas investigaciones se ha denominado como "normalización femenina" y que alude a la continua adaptación de las mujeres para alejarse de los valores a los que tradicionalmente se les asociaba (Aguado Vázquez, 2005). Este proceso está compuesto por el elemento psicológico de la primogenitura, por el cual la herencia parental se deposita de una manera desequilibrada entre la descendencia: el primogénito es el receptor de la imagen ideológica de los progenitores y orienta la identidad del resto de sucesores en un sentido dialéctico que genera una continuidad patrilineal basada en pares opuestos -el primogénito/los otros hijos- (Trivers, 2002). Paralelamente, los hombres catalanes y gallegos asumen el rol de primogénitos de sus respectivos territorios y reciben una herencia basada en la preservación de las lenguas autóctonas. E1 proceso de "otredad" se completa construyendo dialécticamente a las mujeres catalanas y gallegas, las cuales se definen por la herencia contraria a la de los hombres. Así, diferentes mujeres defienden primeramente el castellano como lengua principal en la medida en que, tal y como han indicado algunos estudios, interpretan que hablar catalán o gallego es típico de hombres (González Veira y Seoane Bouzas, 2010: 70). 
Sin embargo, este proceso de definición de identidades masculina y femenina está sujeto a desviaciones que se manifiestan en nuestro grupo de participantes a través de excepciones a los cánones esperados. Algunas mujeres, como Elisa en Cataluña o Cristina en Galicia, juegan papeles consagrados presumiblemente para los hombres y son favorables a las interacciones y medidas normalizadoras que favorecen a las lenguas minorizadas; mientras que algunos hombres, como Eduardo en Galicia y, en ciertas ocasiones, Jaime y Fernando en Cataluña, detentan configuraciones ideológicas contrarias a la promoción de las lenguas minorizadas.

Este tipo de desviaciones de una pretendida norma general corresponde a una segunda oposición en la definición de la "otredad" que se refiere a una imagen ideal en contraposición a la realidad. De esta manera, existe una tensión ideológica entre el hombre que acepta el catalán o gallego -imagen ideal - frente al hombre contrario a estas lenguas -imagen real correspondiente a las excepciones-, y entre la mujer que rechaza el catalán o el gallego - imagen ideal — frente a la mujer que los acepta —imagen real encarnada en informantes como Elisa y Cristina-.

Son precisamente estos sujetos quienes pueden hacer variar las tendencias e inclinar la balanza futura en un sentido $u$ otro. Aquellas personas entrevistadas que revelan cierto desequilibrio de una pretendida regla general son quienes conforman un momento dialéctico caracterizado por la confusión entre dos sistemas dogmáticos (Iliénkov, 1977). Tanto la regla general que establece que las mujeres tienden a elegir la lengua de prestigio, como la contranorma que demuestra casos aislados opuestos ideológicamente, son igualmente lógicos, pero esos individuos "contranormativos" no se encuentran todavía en condiciones de decantarse por una u otra opción. Si la tendencia detectada en la clase alta se mantiene y se fortalece, alimentada por los mismos patrones de la normalización lingüistica que se vienen aplicando, ese momento dialéctico no progresará hacia una tercera etapa de sintesis y, por el contrario, retrocederá garantizando el cumplimiento y la continuidad de las tendencias expuestas.

Cabe puntualizar que mujeres como Elisa y Cristina, aun siendo igual de contranormativas que hombres como Eduardo, Jaime o Fernando, pueden influir menos que los hombres en las medidas adoptadas por la administración o en las ideologías del conjunto de la sociedad porque, en tanto que miembros de estratos sociales, su capacidad de influencia ideológica es más volátil que las fracciones constituidas por los hombres.

\section{Conclusión}

A lo largo de este trabajo se ha propuesto que el factor sexo influye en la configuración ideológica de los hablantes a la hora de valorar las circunstancias interaccionales y las medidas de política lingüística orientadas a beneficiar a las lenguas minorizadas o al castellano. Esta diferenciación no es 
equiparable en Cataluña y en Galicia, por lo que se debe abordar atendiendo a contextos territoriales específicos.

En Cataluña, las mujeres asumen en mayor grado que los hombres la preferencia por el castellano, mientras que los hombres son más proclives a preferir las interacciones y las pautas normativas que benefician al catalán. Sin embargo, ambos grupos no pueden entenderse homogéneamente dado que algunas mujeres entrevistadas representan un prototipo favorable a las medidas impulsadoras del catalán. El modelo de la hegemonía lingüística de Bourdieu (1982a) no se cumple a partir de nuestros datos de Cataluña puesto que existe una ideología asumida por la mayor parte de la muestra que legitima la presencia del catalán, e incluso su dominio, en ámbitos socioeconómicos públicos y privados. Por su parte, la crítica realizada por Woolard (1985) a este modelo es parcialmente válida en nuestra investigación, ya que un perfil de mujer de clase alta de Cataluña está influido poderosamente por valores contrarios a la promoción del catalán.

En Galicia, el sexo no es una variable claramente restrictiva en la conformación de ideologías lingüísticas. El rasgo que se repite sucesivamente es la conciencia lingüística, de manera que, a mayor lealtad consciente hacia el gallego, más favorables son las ideologías de las personas entrevistadas. No obstante, en ciertas ocasiones, las mujeres asumen un rol de mayor sensibilidad hacia el castellano y los hombres, o bien se muestran escépticos en ciertos temas, o bien se decantan ligeramente por una defensa del gallego en cuanto a sus posibles ámbitos de interacción. En este territorio, consideramos que el modelo propuesto por Bourdieu (1982a) tampoco cobra una gran operatividad. La escuela y la familia son las dos instituciones sociales que, según este autor, legitiman la dominación de la lengua de prestigio. Si bien la normalización lingüistica en gallego no la ha hecho erigirse como lengua por defecto en el ámbito escolar, sigue siendo la lengua principal en la transmisión intergeneracional. Por tanto, la desafección que percibimos entre la muestra de informantes procede de una falta de motivación en tanto que el gallego no parece reportar un beneficio socioeconómico relevante.

La clase alta objeto de este estudio no se revela como un grupo homogéneo. En la definición de identidades masculina y femenina, las mujeres forman estratos sociales y los hombres ejercen una mayor influencia social gracias a su constitución en fracciones. Incluso dentro de estos subgrupos existe una fluctuación que impide concebirlos como conjuntos estancos. Aunque se hayan detectado ciertas inclinaciones, en todos los casos encontramos individuos que han mostrado configuraciones ideológicas opuestas a otros informantes de sus respectivos sexos en la asignación de prestigio y legitimidad a las lenguas. Hemos señalado varios prototipos de agentes sociales en una posición socioeconómica favorecida que se derivan de nuestra investigación, pero que no pretenden en ningún caso extrapolarse al resto de la población como modelos únicos. 


\section{REFERENCIAS}

AGUADO VÁZQUEZ, J. C. (2005): “La envidia del pene. Una reinterpretación a la luz de la antropologia del cuerpo", Anales de Antropología, 39 (1), pp. 167-178.

BASTARDAS I BOADA, A. (1994): "Persistència i canvi en el comportament lingüístic: la planificació sociolingüística", Ajuntament d'Alcoi (org.), III Jornades de Sociolingüistica: Normalització $i$ planificació lingüistiques, Alcoy: Ajuntament d'Alcoi, pp. 11-25.

BOURDIEU, P. (1982a): Ce que parler veut dire. L'économie des échanges linguistiques, París: Fayard.

BOURDIEU, P. (1982b): Leçon sur la Leçon, París: Minuit.

BOURDIEU, P. (1979): La distinction, critique sociale du jegement, París: Minuit.

CAMERDATA (2015): "Rankings y sectores empresariales", Camerdata. Disponible en: http://www.camerdata.es/php/Productos/rankings.php (Fecha de consulta: 20/05/2018).

COATES, J. (2013): Women, Men and Language: A Sociolinguistic Account of Gender Differences in Language, Londres / Nueva York: Routledge.

ECKERT, P. (2000). Linguistic Variation as Social Practice, Oxford: Blackwell.

ECKERT, P. (1989): "The whole woman: sex and gender differences in variation", Language variation and change, 1, pp. 245-267.

ECKERT, P. \& MCCONNELL-GINET, S. (2003): Language and Gender, Londres: Cambridge University Press.

ECKERT, P. \& MCCONNELL-GINET, S. (1999): "New generalisations and explanations in language and gender research", Language in Society, 28, pp. 185201.

EISIKOVITS, E. (1998): "Girl-talk / boy-talk: sex differences in adolescent speech", Coates, J. (ed.): Language and Gender: A Reader, Oxford: Blackwell, pp. 42-54.

EL ECONOMISTA (2015): "Ranking de empresas españolas por facturación", El Economista. Disponible en: http://ranking-empresas.eleconomista.es/ (Fecha de consulta: 20/05/2018).

EXPANSIÓN (2015): "El top 100 de las empresas que más empleo generan en España", Expansión. Disponible en: http://www.expansion.com/empresas/2015/09/11/55f3368fe27 04e77618b4587.html (Fecha de consulta: 20/05/2018).

GLÜCK, H. (1979): "Der Mythos von den Frauensprachen", Andersen, H., Markmann, S. y Wigger, A. (eds.): Sprache und Geschlecht, Osnabrück: Universität Osnabrück, pp. 60-95.

GONZÁLEZ VEIRA, A. \& SEOANE BOUZAS, N. (2010): "Un achegamento aos preconceptos contra o Galego por parte das mulleres a través das súas palabras", Mosquera Carregal, X. M. (ed.): Lingua e xénero: VIXornadas sobre lingua e usos, A Coruña: Universidade da Coruña, pp. 63-77.

ILIÉNKOV, E. V. (1977): Lógica dialéctica, Traducido por Jorge Bayona, Moscú: Progreso.

INSTITUT D'ESTADÍSTICA DE CATALUNYA (2015): Coneixement de llengües: català, castellà, anglès $i$ francés, Barcelona: Generalitat de Catalunya. 
INSTITUT D'ESTADÍSTICA DE CATALUNYA (2004): Estadistica d'usos lingüistics a Catalunya 2003, Barcelona: Generalitat de Catalunya.

INSTITUTO GALEGO DE ESTATÍSTICA (2013): Enquisa de condicións de vida das familias. Módulo de coñecemento e uso do galego 2013, Santiago de Compostela: Instituto Galego de Estatística.

INSTITUTO GALEGO DE
ESTATÍSTICA (2001): "Censo de poboación e vivendas 2001", IGE. Disponible en: http:/ / www.ige.eu/web/mostrar_actividade_estatistica.jsp?idioma $=$ gl\& $\&$ codigo $=$ 0206002002 (Fecha de consulta: 05/07/2018).

INSTITUTO NACIONAL DE ESTADÍSTICA (2015): "Ganancia media anual por trabajador - Año 2013”, INE. Disponible en: http:/ / www.ine.es/dyngs/INEbase/es/operacion.htm?c=Estadis-

tica_C\&cid $=1254736061721 \%$ menu=ultiDatos\&idp $=1254735976596 \quad(\mathrm{Fe}-$ cha de consulta: 13/06/2018).

LORENZO SUAREZ, A. (2009): "A situación actual da lingua galega: unha ollada desde a sociolingüística e a política lingüística", Galicia 21, Issue A, pp. 20-39.

MACAULAY, R. (1978): "Variation ans consistency in Glaswegian English", Trudgill, P. (ed.): Sociolinguistic Patterns in British English, Londres: Edward Arnold, pp. 132-143.

MOURE, T. (2010): "Falarmos galego as mulleres, por que non?", Mosquera Carregal, X. M. (ed.), Lingua e xénero: VI Xornadas sobre lingua e usos, A Coruña: Universidade da Coruña, pp. 147-169.
MULAC, A. \& BRADAC, J. (1995): "Women's style in problem solving interactions: powerless or simply feminine?", Kalbfleisch, P. y Cody, M. (eds.): Gender, Power and Communication, Hillsdale, NJ: Lawrence Erlbaum, pp. 83-104.

PINTO PAJARES, D. (2018): Representaciones ideológicas de las lenguas: análisis comparativo de las ideologías lingüisticas en las clases altas gallega y catalana. Tesis doctoral, Vigo: Universidad de Vigo.

POULANTZAS, N. (1968): Pouvoir politique et classes sociales de l'état capitaliste, París: Maspéro.

PUJOLAR, J. (2003): "La construcció del gènere en la interacció informal cara a cara: aspects teòrics i metodològics", Estudios de Sociolingüística, 4 (2), pp. 485-503.

RAMALLO, F. (2013): "Neofalantismo", Gugenberger, E., Monteagudo, H. y Rei-Doval, G. (eds.): Contacto de linguas, hibridade, cambio: contextos, procesos e consecuencias, Santiago de Compostela: Consello da Cultura Galega, pp. 245-258.

REAL ACADEMIA GALEGA (2003): $O$ galego segundo a mocidade, A Coruña: Real Academia Galega. ROSALDO, M. Z. \& LAMPHERE, L. (eds.) (1974): Woman, Culture, and Society, Stanford: Stanford University Press.

ROSENBLUM, K. (1986): "Revelatory or purposive? Making sense of a 'female register", Semiotica, 59 (1), pp. 157-170.

SANMARTÍN REI, G. (2009): Nos camiños do entusiasmo, Vigo: Xerais.

SANMARTÍN REI, G. (2002): Lendo nas marxes. Lingua e compromiso nos paratextos (18631936), A Coruña: Espiral Maior. 
SERRANO, M. (2008): "El rol de la variable sexo o género en sociolingüística: ¿diferencia, dominio o interacción?, Boletín de Filología, 43, pp. 175-192.

SORIANO, D. (2015): "Los ricos en España, ni son tantos ni son tan ricos", Libremercado. Disponible en: http://www.libremercado.com/2015-05-14/los-ricos-en-espana-ni-son-tantosni-son-tan-ricos-1276547799/ (Fecha de consulta: 13/06/2018)

THORNE, B. \& HENLEY, N. (1975): Language and Sex: Difference and Dominance, Rowley, MA: Newbury House.

TRIVERS, R. (2002): Natural Selection and Social Theory: Selected Papers of Robert Trivers, Nueva York: Oxford University Press.
TRUDGILL, P. (1983): On Dialect: Social and Geographical Perspectives, Oxford: Basil Blackwell.

TRUDGILL, P. (1974): The Social Differentiation of English in Norwich, Cambridge: Cambridge University Press.

WOOLARD, K. (1985): "Language variation and cultural hegemony: toward an integration of sociolinguistic and social theory", American Ethnologist, 12 (4), pp. 738-748.

WOOLARD, K. (1997): "Identidades de clase y género en los proyectos lingüísticos nacionales: Alguna evidencia desde Cataluña", $R e$ vista de Antropología Social, 6, pp. 193-213.

WRIGHT, E. O. (2004): Class Counts, Cambridge: Cambridge University Press. 